\title{
Transplant-acquired food allergy: current perspectives
}

This article was published in the following Dove Press journal: Journal of Asthma and Allergy

\author{
Shweta S Hosakoppal \\ Paul J Bryce \\ Division of Allergy and Immunology, \\ Department of Medicine, Feinberg \\ School of Medicine, Northwestern \\ University, Chicago, IL, USA
}

\begin{abstract}
Mechanisms that regulate the tolerance to dietary proteins or the loss of this and subsequent development of disease are poorly understood. In food allergy, there is growing awareness of the urgency in understanding these events to aid in the development of next-generation therapies and interventions. This review focuses on the accumulating evidence related to food allergy that develops after transplantation. This intriguing immunological phenomenon has been described in several different types of transplant settings and to variety of different foods. We outline these studies and the evidence from them that support transplant-acquired food allergy being a process regulated by both the donor allergic status and the recipient genetics and treatments. A number of key risk factors seem prevalent throughout transplant-acquired food allergy and include type of transplant, age and general health of the recipient, modality of immunosuppression and potentially the genetics of both donor and recipient. Importantly, these studies provide a window into better general understanding of food allergy, and facilitate clearer understanding of the critical immunological and epidemiological factors needed to allow the adoptive transfer of a food-specific allergic disease from one individual to another.
\end{abstract}

Keywords: food, allergy, transplantation, atopy

\section{Introduction}

The acquisition of food allergy after bone marrow and solid organ transplantation by previously non-allergic transplant recipients has now become a well-established phenomenon. One of the first reported cases of this dates back to 1989, when a previously non-allergic adult male developed severe peanut allergy post liver and kidney transplant. ${ }^{1}$ Since then, a number of additional cases have been reported, with those involving liver transplantations and pediatric recipients being the most common. While the underlying causes remain unclear, due in part to the high degree of variability among cases, there are a number of proposed mechanisms that have emerged, such as those involving cell transfers and the type of immunosuppressant therapy administered. Importantly, these mechanisms provide a window into better understanding of the potential mechanisms that underlie the loss of tolerance to dietary antigens and development of food allergy generally.

In this review, we will attempt to provide a clear understanding of food allergy before examining its significance and association with transplantation. As treatment options are currently limited, the ability to diagnose and identify food allergy among transplant recipients is imperative, especially due to the potentially life-threatening anaphylactic response that can occur upon contact with the food allergen. We will address
Correspondence: Paul J Bryce

Division of Allergy and Immunology,

Department of Medicine, Feinberg School of Medicine, Northwestern University,

240 E. Huron Street, Chicago, IL

606II, USA

Tel +I 3 I 25030077

Email p-bryce@northwestern.edu 
the mechanisms behind the development and risk factors of food allergy, the epidemiology of transplant-acquired food allergy, the individuals most at risk, and finally the implications of science of this phenomenon.

\section{Food allergy background}

Food allergy is defined as an immunologically mediated adverse response to food ${ }^{2}$ and is of growing concern due to its rising prevalence across the world. Recent numbers show that up to 15 million individuals are food allergic in the USA, ${ }^{3}$ with the majority being children. The most common food allergens among allergic patients include milk, egg, peanut, tree nuts, shellfish, fish, wheat, sesame, and soy. While reactivity to some foods is often outgrown early on in life, including milk, egg, soy and wheat, allergies to other foods can often persist well into adulthood, including peanut, tree nut, fish, and shellfish. ${ }^{4}$ Exposure to these allergens can elicit a range of clinical symptoms ranging from mild to life-threatening in allergic patients and can involve multiple organ systems, including the skin, gastrointestinal (GI), and respiratory tracts. The most severe reactions can result in anaphylaxis, which is potentially fatal if life-saving medications are not administered. ${ }^{5}$

Currently, the main approved treatment options available for food allergic patients involve strict avoidance diets and the administration of epinephrine in case of accidental exposures or ingestions. ${ }^{3}$ Because there is no cure, these limited treatment strategies can be taxing for both the patients and their families, affecting quality of life drastically, as shown through health-related quality of life survey data. ${ }^{6}$ In addition, food allergy is a significant economic burden on US households, with an estimated $\$ 24.8$ billion going toward treatment costs. ${ }^{7}$ Another important issue with food allergy is its comorbidity with other allergic conditions. A study on 3,321 students found that the presence of food allergy increases the association risk for having other allergic diseases, including atopic dermatitis, bronchial asthma, and allergic rhinitis. ${ }^{8}$ For these reasons, it is necessary to better understand the underlying mechanisms behind food allergy, as a way to improve the development of novel treatments that reduce and avoid these burdens.

\section{How and why do we become food allergic?}

Mechanistically, current knowledge shows that there are several important processes that may play a central role in the progression toward food allergy. These processes include the key concepts of development of oral tolerance, sensitization to food allergens, anaphylactic reactivity to allergens, and finally, a developing idea of non-responder tolerance. ${ }^{3}$ Oral tolerance describes the body's natural response of consuming food without producing an adverse immune response. This phenomenon appears to be regulated via specific gut-resident cells, including subtypes of dendritic cells and $\mathrm{T}$ regulatory cells, that are able to act and maintain a tolerant environment toward food antigens. However, signals that are mechanistically relatively unclear, but proposed to include changes in the microbiome, cytokine imbalances, Th2 skewing, and loss of epithelial barrier integrity, can tip the balance away from tolerance. This shift results in an individual becoming sensitized and as a result, clinically food allergic, whereby an early, acute reaction occurs immediately upon allergen ingestion, followed in some people by a late-phase response hours later. This immune response is principally due to the action of the antibodies immunoglobulin $\mathrm{E}(\mathrm{IgE})$ and $\mathrm{IgG}$, the release of pre-formed mediators such as histamine by mast cells and basophils, and the recruitment and build up of inflammatory cells. Recent work has also suggested the idea of non-responder tolerance, wherein clinical tolerance to food exposure is exhibited despite the presence of specific $\operatorname{IgE}$ toward that antigens in that food, most likely due to the activity of T regulatory cells. ${ }^{3}$

\section{Who is at risk for food allergy?}

As a means to counter the rising prevalence of food allergy, there have been several investigations into risk factors for developing food allergy. Epidemiological studies have found that risk factors can include sex (male children and female adults), race (Asian and African-American children), atopy (comorbidities with other atopic disorders, particularly atopic dermatitis), diet (deficiencies of either vitamin D, antioxidants, or omega-3-polyunsaturated fats, obesity, and the use of antacids), hygiene, and maternal diet. ${ }^{9}$ A particular risk factor of significant interest lies with genetics, which can include family history of food allergy and mutations in specific genes. One study found a 7-fold increase in the incidence of peanut allergy for a child whose parent or siblings had peanut allergy, suggesting the presence of a genetic predisposition. ${ }^{10}$ Twin studies also predict a high level of heritability, as there is a $64 \%$ chance a child will have peanut allergy if his or her monozygotic twin has peanut allergy. ${ }^{11}$ Other studies have looked at the association between genetic mutations and food allergy. Specifically, a significant relationship was found between mutations in the filaggrin gene, which codes for an epidermal protein critical to skin barrier function, and food allergy in children. ${ }^{12}$ These studies together suggest that the 
development of food allergy can involve both environmental and genetic components. Recently, an emerging risk factor for food allergy that provides fascinating evidence in support of the overarching idea of both genetic and environmental influences is a history of organ transplantation, which will be the topic of this review.

\section{Introduction to transplant-acquired food allergy}

Organ transplantation is a life-saving procedure performed in a variety of clinical settings, including situations of end-stage organ failure, cancer, and autoimmune disorders. According to the Center for Disease Control, there are an estimated 75,000 Americans on the organ transplant waitlist. Advancements in the field have made transplantation procedures relatively safe with only occasional adverse reactions that can include serious illness, graft rejection, and in rare cases death. A more surprising post-transplantation adverse reaction is the development of food allergy, described as occurring to a variety of allergens, including but not limited to nut, milk, egg, wheat, and fish. The onset of these transplant-acquired food allergies has been reported from days to months after transplant and to several different types of transplants, including bone marrow, liver, kidney, heart, intestine, and lung, as well as been described in both adult and pediatric populations. This review aims to discuss prevailing theories and opinions on how and why certain individuals seem to develop transplant-acquired food allergies and what this route toward food allergy means for our understanding of the mechanisms and risk factors for food allergy in general.

\section{Epidemiology}

Food allergy has been estimated to affect around $8 \%$ of the general pediatric population, ${ }^{9}$ whereas the frequency of transplant-acquired food allergy in children has been stated as high as $17 \%,{ }^{13}$ seen in the setting of liver transplant. With the prevalence of the latter being higher, the development of such food allergies in children is likely related to factors associated with the transplantation, making this an important topic of study. One of the earliest reported cases of transplantacquired food allergy involved bone marrow transplantations in 2 non-allergic children who, within months of the procedures, developed allergies to a range of foods; the donor/ recipient pairs were siblings and the donors had a history of atopy. ${ }^{14,15}$ About a decade later, the first 2 cases describing the development of food allergy after solid-organ transplantation surfaced. ${ }^{1,16}$ Since then, a growing number of additional cases have been reported involving different factors such as type of organ, ages of recipients, time to food allergy onset, food allergens, donor allergic status, and family history (Table 1).

\section{Risk factors}

Studies of transplant-acquired food allergy have shown that risk factors appear to lie with both recipient (patient)-specific and transplant (donor)-specific factors, as highlighted by a case of 2 transplant recipients receiving organs, albeit different tissues, from the same donor but only one of the recipients developing food allergy. ${ }^{1}$ This complexity makes it difficult to establish what the key factors might be but there have been common threads observed within transplant-acquired food allergy that are outlined below.

\section{Type of organ transplant}

Several reports have shown that transplant-acquired food allergies are more common after liver transplantation specifically. The frequency of food allergy post liver transplantation has been reported to range from $5.7 \%{ }^{17}$ to $37 \%{ }^{18}$ in pediatric populations, which is higher than reports for any other organ transplantation. A retrospective review of 189 kidney and/or liver transplant patients found that all of those who developed food allergy post-transplantation were recipients of liver, but not kidney transplants. ${ }^{19}$ This is interesting as kidney transplantations are in fact more common than liver, suggesting that it is not the frequency of the particular type of transplant that is at play here and, instead, perhaps something unique about the structure and immunology of the liver that is causing the allergic condition in these patients. ${ }^{20}$

There are some proposed reasons for the development of food allergy most exclusively after liver transplantations. For example, the liver homes pluripotent hematopoietic stem cells which, upon transfer from donor to recipient, are capable of generating lymphocytes ${ }^{21}$ and these lymphocytes may be sensitized to a particular allergen and potentially produce an immune response in the recipient upon allergen exposure. The transfer of such sensitized lymphocytes is more probable through the liver compared to other organs, due to its larger size and vascularity. ${ }^{22}$ In addition, transfer of liver-resident dendritic cells and sinusoidal endothelial cells to the recipient can skew naive CD4+ T cells toward a Th2 phenotype, promoting an $\mathrm{IgE}$ response to antigen. ${ }^{23}$

Other possible explanations for this selectivity for liver transplants involve the recipient's liver dysfunction prior to transplantation. A study of children undergoing liver transplantation found both $\operatorname{IgE}$ sensitization of foods and elevated levels of total IgE present pre-transplantation. ${ }^{24}$ It is possible that some children with liver failure are actually food 


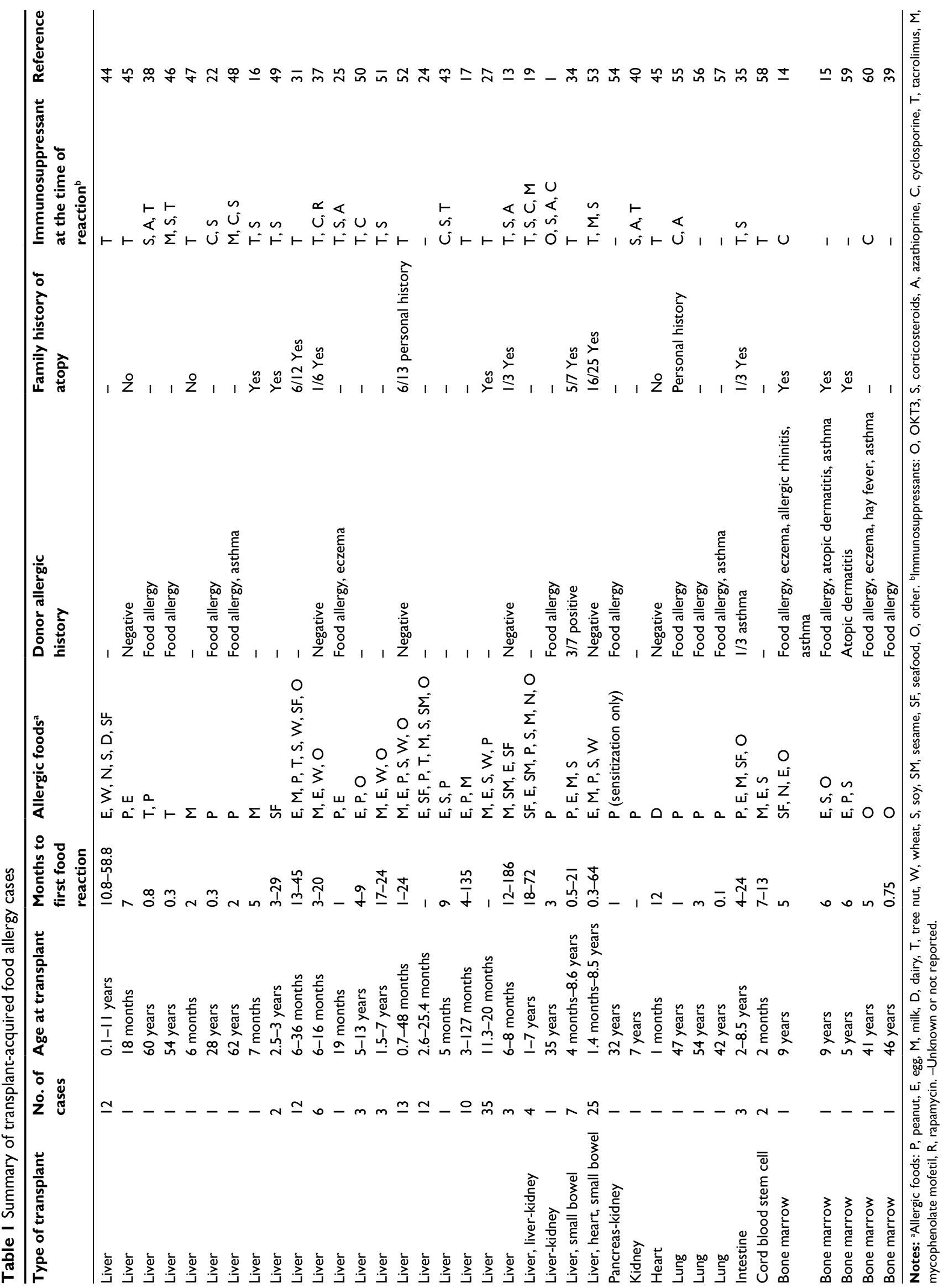


allergic before transplantation, but there are no discernable signs because of immune dysfunction. Transplantation of a healthy liver can reverse this, resulting in the presentation of food allergy symptoms. ${ }^{25}$

\section{Age of recipient}

Transplant-acquired food allergies have been reported in both adult and pediatric patients but data show that the frequency of cases is significantly higher in children. This is perhaps not surprising given that food allergy prevalence is generally higher for children compared to adults (recent numbers estimate $8 \%$ in children and $5 \%$ in adults). ${ }^{9}$ Boyle et al provide intriguing evidence for age-associated influences when they described a case of a split liver graft from a donor with ambiguous allergic history. The donor's left liver lobe was given to a 19-month-old patient who developed peanut and egg allergy, while the right lobe was given to a 35-year-old patient who developed no food allergies. ${ }^{25}$ Both patients were administered similar immunosuppressant therapy, making their age the strongest differentiating factor. In addition, a Korean study of 130 liver transplantation cases and a Turkish study of 165 such cases both found that younger age at the time of transplantation was a significant factor in the onset of food allergy. ${ }^{26,27}$ These case reports provide noteworthy support for the notion that children are more likely than adults to develop food allergy after transplantation. Likely reasons for this phenomenon will be addressed below, under possible mechanisms of transplant-acquired food allergy.

\section{Type of immunosuppressant therapy}

As a means to improve graft survival, the administration of immunosuppressant drugs is required post transplantation. While the 1980s introduction of immunosuppressants increased the rates of 1-year graft survival to over $80 \%,{ }^{28}$ some evidence suggests that some of these agents may actually influence the development of food allergy after transplantation.

For example, there is an increased frequency of food allergy in children receiving tacrolimus from $6 \%$ to $20 \%,{ }^{29}$ especially after liver grafts. ${ }^{30}$ One of the earliest documented cases of transplant-acquired food allergy was on a 7-monthold liver recipient who was on tacromilus ${ }^{16}$ and since then, the reports on patients taking this drug who developed food allergy has increased. A study of 560 pediatric liver recipients found that $10 \%$ of the children developed food-induced angioedema (a food allergy-associated clinical response) while taking tacrolimus. ${ }^{31}$ Another study of liver transplant patients taking varied immunosuppressant regimens described that those who developed food allergy symptoms were most commonly the patients taking tacrolimus. ${ }^{32}$ This phenomenon is not restricted to liver transplants as a 1996 study found that 11 out of 49 heart transplant patients who received tacrolimus (Prograf ${ }^{\circledR}$; Astellas Pharma, Tokyo, Japan) developed allergic disease. ${ }^{33}$ Such cases have also been reported after kidney ${ }^{29}$ and small bowel transplants. ${ }^{34,35}$

However, while this connection to tacrolimus is evident, there have also been incidents of food allergy development after the use of other immunosuppressant drugs, including cyclosporine. ${ }^{1,31}$ A study of kidney-transplant recipients found that $8 \%$ of patients on cyclosporine developed clinically relevant allergy versus $15 \%$ for those taking tacrolimus. ${ }^{29}$ However, when liver transplant patients who developed food-induced angioedema after tacrolimus were switched to cyclosporine, they were no longer reactive to the foods that had initially caused allergic symptoms. ${ }^{31}$ Other common immunosuppressive treatments worth mentioning include mycophenolate mofetil and prednisone, more commonly given after renal transplants. It is intriguing to consider the possibility that preferred administration of mycophenolate and prednisone to kidney recipients might have influenced the discrepancy in transplant-acquired food allergy seen between liver and kidney recipients that was discussed above. ${ }^{19}$

\section{Family history of atopy}

It has been suggested that transplant patients who develop food allergy may be doing so because of their atopic background, as many of these individuals have a family history of atopy. In one report, $50 \%$ of liver recipients who developed food allergy had a family history of atopic disorders, including allergic rhinitis, asthma, eczema, food-induced angioedema, or drug-related urticaria. ${ }^{31}$ Such reports imply a likely genetic predisposition that exists, making family history of atopic disorders a possible recipient risk factor for transplant-acquired food allergy.

\section{Donor-specific factors}

Transplant recipients may be at risk for developing food allergy depending on factors related to the donor. The donor's atopic history may be important, as seen in the case of a peanut allergic donor whose liver and right kidney were given to a man who later became allergic to peanuts post transplant. ${ }^{1}$ This, however, may not be the sole factor involved as the same allergic donor's pancreas and left kidney were given to a different recipient who did not show signs of food allergy. Similarly, Boyle et a ${ }^{25}$ report a case of a 19 -month-old patient developing food allergy after receiving a liver transplant from 
a donor with severe eczema and possible food allergy. Aside from atopic history, Ozdemir also describes that transplantacquired allergies can be related to young donor age. ${ }^{30}$

\section{Mechanisms}

Transplant-acquired food allergies have been receiving increasing attention, especially since their exact pathogenesis is unknown. While the precise reason for the development of this allergic condition has not been established, there are a number of mechanisms that have been proposed. It is important to note that it is unlikely that just one of these mechanisms alone is the sole explanation of these food allergies, rather a combination of multiple factors is more probable, both between patients and within the same patient. Similarly, none of these mechanistic theories have received thorough experimental testing to define their necessity or sufficiency to the transplant-acquired food allergy phenomena.

\section{Transfer of donor allergen-specific, bound lgE}

The most frequently proposed mechanism is the passive transfer of preformed donor IgE during the transplantation procedure. The first case report of transplant-acquired food allergy alluded to the idea that the liver and kidney recipient developed peanut allergy (while the pancreas and kidney recipient did not) because the donor's liver alone may have been the source of peanut-specific IgE. Many have deemed this mechanism unlikely as IgE has a half-life of only a few days and the previously described peanut allergy manifested months after the transplantation. However, Castells and Boyce $^{36}$ found that IgE when bound to cells can have a halflife that exceeds 120 days. This suggests that the donor's allergen-specific IgE, if bound to mast cells in the transplant recipient, can survive long enough to cause degranulation upon exposure to the particular food allergen. It would likely be this bound form of IgE that could persist and cause an allergic reaction.

Support for this mechanism would come from considering IgE levels of transplant recipients pre- and post-transplant. While there are several reports of elevated total and allergenspecific IgE levels in post-liver transplant patients, ${ }^{18,31}$ there are relatively few that describe IgE levels pre-transplant. Granot et al found that the mean total IgE levels for post-liver transplant recipients was $83 \mathrm{IU} / \mathrm{mL}$ for those younger than 3 years (normal $<45 \mathrm{IU} / \mathrm{mL}$ ) and $557 \mathrm{IU} / \mathrm{mL}$ for the older patients (normal $<87 \mathrm{IU} / \mathrm{mL}$ ). ${ }^{32}$ The few cases that do report total IgE pre-transplant found these levels to be elevated in some of the patients as well. ${ }^{24,37}$

\section{Transfer of donor allergen-specific lymphocytes}

The transfer of allergen-specific B or T lymphocytes along with the donor organ is another possible mechanism. As previously discussed, the liver is the primary source of hematopoietic stem cells, which are able to generate allergen-specific lymphocytes. In fact, hematopoietic lymphoid tissue is also transferred during bone marrow and small bowel transplantations. In their review, Needham et $\mathrm{a}^{20}$ describe how these carrier lymphocytes can persist for months in the recipient and could explain the commonly seen delay in food allergy onset in transplant recipients. In addition, donor liver-resident dendritic cells that are transferred with the organ may skew recipient naive $\mathrm{T}$ lymphocytes toward $\mathrm{Th} 2$, promoting an IgE-mediated response to antigen. ${ }^{23}$

To investigate this mechanism, 2 methods of analyses have been used. First, several studies have tested for microchimerisms in the blood and skin of transplant recipients. This involves DNA extraction and amplification for the detection of donor-origin cells in order to find differences in HLA genotypes. In the case of a peanut allergic donor whose liver and kidney was given to a patient who developed food allergy, microchimerism was detected in the skin of the recipient. ${ }^{1}$ However, another report of a liver transplant patient with post-transplant allergy found no donor-specific HLA alleles in the blood or skin. ${ }^{38}$

More recently reported, chromosomal FISH analysis has been applied to test chimerism, which uses fluorescent labeling to identify particular chromosomal regions. The particular case involved a hematopoietic cell transplantation from a female kiwi allergic donor to a male recipient, who developed kiwi allergy after transplantation; to confirm that the female donor's cells were the source of the allergy, PBMCs from the male recipient were analyzed using centromeric probes and the resulting detection signals included 2 for the $\mathrm{X}$-chromosome and 0 for the Y-chromosome, ${ }^{39}$ indicative of complete chimerism and donor-driven responses; such chimerism is likely quite different from those seen in solid organ transplant. The report also found a large population of donor-derived CD86+ memory $\mathrm{T}$ cells circulating in the recipient, which could have contributed to maintaining the kiwi-specific IgE response. ${ }^{39}$

It is critical to highlight that such mechanisms involving the transfer of allergen-specific immunoglobulins or lymphocytes would only account for the development of food allergy in transplant patients if the donor is also allergic to the same foods, which is frequently not the case. Boyle et al, ${ }^{25}$ for example, concluded that of 28 transplant recipients who 
developed food allergy, only 3 of their donors had a confirmed food allergy.

\section{Action of immunosuppressants}

To prevent graft rejection, immunosuppressive drugs are administered to suppress cells of the immune cell, primarily $\mathrm{T}$ and $\mathrm{B}$ lymphocytes. As a result, it is expected that transplant recipients using immunosuppressants would actually not develop any kind of sensitization or clinical symptoms of allergy because the IgE pathway is being repressed. Furthermore, some of these drugs are even used to treat allergic disorders, including cases of severe atopic dermatitis and asthma. ${ }^{40}$ It is, therefore, surprising that a transplant patient's immunosuppressive regimen may actually be the cause of their allergy.

Immunosuppressants such as tacrolimus and cyclosporine are known interleukin-2 (IL-2) inhibitors and are thereby capable of suppressing the T-helper cell responses, particularly Th1. Th1 and Th2 lymphocytes exist in a negative feedback pathway and as a result, the suppression of Th1 lymphocytes promotes a robust Th2 response. This Th1/Th2 imbalance promotes the production of $\operatorname{IgE}$ and the activation of mast cells and eosinophils. Tacrolimus in particular, with a greater potency than cyclosporine, has been shown to enhance the production of the $\mathrm{IgE}$ and eosinophil-associated Th2 cytokines, IL-5 and IL-13. ${ }^{19}$

Tacrolimus has also been shown to increase intestinal permeability which can enhance a patient's systemic exposure to allergic proteins and further skew toward a Th2 cytokine and IgE-mediated response. ${ }^{41}$ Gabe et $\mathrm{al}^{42}$ demonstrated that tacrolimus inhibits mitochondrial energy production, leading to the increased intestinal permeability and endotoxemia. However, nonsteroidal anti-inflammatory drugs also alter cellular energy production and increase intestinal permeability but have not shown to have any kind of association with the development of food allergy. This means that while immunosuppressants may cause significant immune and intestinal changes, they are unlikely the underlying cause behind transplant-acquired food allergies. ${ }^{25}$

Mycophenolate mofetil is an immunosuppressive drug given particularly to kidney transplant patients. Mycophenolate is a known suppressor of B-lymphocyte activity and as a result, reduces IgE production. ${ }^{30}$ Such mechanisms may help explain why kidney transplant patients do not develop food allergy as often as recipients of other organs, especially liver. This idea is supported by a case report that describes a decrease in food-specific IgE after the addition of mycophenolate to an initial immunosuppressive regimen of only tacrolimus. However, the same report highlights several cases of patients on a regimen of both tacrolimus and mycophenolate, who still developed food allergy. They comment on the necessary for dose-ranging studies to better understand the relationship between these drugs. ${ }^{43}$

\section{Immature $\mathrm{Gl}$ and immune systems of children}

A particular case report described a split liver graft, in which the left lobe from a presumed peanut allergic donor was transplanted to a 19-month-old child, who developed egg and peanut allergy, and the right lobe given to a 35-year-old adult, who did not develop food allergy. ${ }^{25}$ Both recipients were administered tacrolimus, suggesting that a possible mechanism could exist outside of the type of organ transplant and immunosuppressant regimen. Mechanistically, the age of the recipient could play a role, as children are known to have both an immature GI tract and immune system, which can enhance the systemic exposure to dietary antigens. ${ }^{20}$ Others have suggested that children are more likely to develop transplant-acquired food allergies because of their limited intake of food antigens prior to transplantation. ${ }^{24}$

\section{Implications}

The implications of this review are aligned with both the need to better understand the clinical risk factors and underlying mechanisms that relate to transplant-acquired food allergy. There are studies that report the resolution of food allergies and associated symptoms in some transplant patients over time, suggesting the transient nature of this phenomenon, perhaps attributable to reduced immunosuppression, strict avoidance diets, or simply outgrowth of the allergy. ${ }^{13,30}$ Despite this, there are still a significant number of patients who remain intolerant to particular foods for many years. As described earlier, these food allergic patients have limited treatment options and must usually adopt a strict avoidance diet, which can greatly impact quality of life. As some food allergy reactions can be potentially life-threatening, the proper monitoring of transplantation procedures is necessary to reduce the prevalence of these transplant-acquired food allergies and the potential they bring for severe clinical reactions. Transplant physicians and recipients should be aware of the possible risk of developing a food allergy, the symptoms of an allergic reaction, and how to self-administer epinephrine if ever necessary. The donor's allergic status, recipient's allergic status pre-transplantation, and the recipient's family history of atopy should be documented and discussed to find any potential risk factors. In addition, monitoring IgE levels 
and administering skin prick tests for particular allergens may be beneficial for both pre- and post-transplantation. This is especially recommended for pediatric patients receiving liver transplantations and undergoing tacrolimus immunosuppression, as these individuals appear to be most at risk.

\section{Conclusion}

Transplant-acquired food allergies have become a welldescribed phenomenon since the first reports of it from the 1980s. While these food allergies can develop from several days to months after multiple types of transplantations in recipients of all ages, the most common cases involve pediatric liver transplantations. There are several factors that may make some recipients more prone to food allergy, including type of organ transplant, age of recipient, immunosuppressive regimen, family history of atopy, and donor allergic status. There is speculation regarding the exact cause of these food allergies, especially given the irregularity between reported cases, but there are proposed mechanisms for its pathogenesis. The passive transfer of IgE, passive transfer of lymphocytes, Th2 skewing and increased intestinal permeability due to immunosuppressive treatment, and the immature GI and immune systems of children are the most widely reported mechanisms thus far. With the scarcity of food allergy treatment options and the potentially life-threatening repercussions, it is important to be able to recognize the risk of developing an allergy post-transplantation. Further studies are needed on this topic to better understand the mechanisms behind transplant-acquired food allergies as means to reduce its prevalence and associated clinical reactions.

\section{Disclosure}

The authors report no conflicts of interest in this work.

\section{References}

1. Legendre C, Caillat-Zucman S, Samuel D, et al. Transfer of symptomatic peanut allergy to the recipient of a combined liver-and-kidney transplant. N Engl J Med. 1997;337(12):822-824.

2. Sicherer SH, Sampson HA. Food allergy. J Allergy Clin Immunol. 2010;125(2 Suppl 2):S116-S125.

3. Johnston LK, Chien KB, Bryce PJ. The immunology of food allergy. J Immunol. 2014;192(6):2529-2534.

4. Wood RA. The natural history of food allergy. Pediatrics. 2003;111(6 Pt3): 1631-1637.

5. Sampson HA. Update on food allergy. J Allergy Clin Immunol. 2004; 113(5):805-819; quiz 820.

6. Flokstra-de Blok BM, Dubois AE, Vlieg-Boerstra BJ, et al. Healthrelated quality of life of food allergic patients: comparison with the general population and other diseases. Allergy. 2010;65(2):238-244.

7. Gupta R, Holdford D, Bilaver L, Dyer A, Holl JL, Meltzer D. The economic impact of childhood food allergy in the United States. JAMA Pediatr. 2013;167(11):1026-1031.
8. Kijima A, Murota H, Takahashi A, et al. Prevalence and impact of past history of food allergy in atopic dermatitis. Allergol Int. 2013;62(1):105-112.

9. Sicherer SH, Sampson HA. Food allergy: epidemiology, pathogenesis, diagnosis, and treatment. JAllergy Clin Immunol. 2014;133(2):291-307; quiz 308 .

10. Hourihane JO, Dean TP, Warner JO. Peanut allergy in relation to heredity, maternal diet, and other atopic diseases: results of a questionnaire survey, skin prick testing, and food challenges. $B M J$. 1996;313(7056):518-521.

11. Sicherer SH, Furlong TJ, Maes HH, Desnick RJ, Sampson HA, Gelb BD. Genetics of peanut allergy: a twin study. J Allergy Clin Immunol. 2000;106(1 Pt 1):53-56.

12. Venkataraman D, Soto-Ramirez N, Kurukulaaratchy RJ, et al. Filaggrin loss-of-function mutations are associated with food allergy in childhood and adolescence. J Allergy Clin Immunol. 2014;134(4):876-882. e4.

13. Mavroudi A, Xinias I, Deligiannidis A, Parapanissiou E, Imvrios G. Long term outcome of acquired food allergy in pediatric liver recipients: a single center experience. Pediatr Rep. 2012;4(1):e6.

14. Tucker J, Barnetson RS. Atopy after bone marrow transplantation. $\mathrm{Br}$ Med J. 1985;290(6462):116-117.

15. Walker SA, Riches PG, Wild G, et al. Total and allergen-specific IgE in relation to allergic response pattern following bone marrow transplantation. Clin exp Immunol. 1986;66(3):633-639.

16. Lacaille F, Laurent J, Bousquet J. Life-threatening food allergy in a child treated with FK506. J Pediatr Gastroenterol Nutr. 1997;25(2):228-229.

17. Shroff P, Mehta RS, Chinen J, Karpen SJ, Davis CM. Presentation of atopic disease in a large cohort of pediatric liver transplant recipients. Pediatr Transplant. 2012;16(4):379-384.

18. Lee JH, Park HY, Choe YH, Lee SK, Lee SI. The development of eosinophilic colitis after liver transplantation in children. Pediatr Transplant. 2007;11(5):518-523.

19. Levy Y, Davidovits M, Cleper R, Shapiro R. New-onset post-transplantation food allergy in children is it attributable only to the immunosuppressive protocol? Pediatr Transplant. 2009;13(1):63-69.

20. Needham JM, Nicholas SK, Davis CM. Food allergies developing after solid organ transplant. Pediatr Transplant. 2015;19(8):827-835.

21. Collins RH Jr, Anastasi J, Terstappen LW, et al. Donor-derived longterm multilineage hematopoiesis in a liver-transplant recipient. $N$ Engl J Med. 1993;328(11):762-765.

22. Trotter JF, Everson GT, Bock SA, Wachs M, Bak T, Kam I. Transference of peanut allergy through liver transplantation. Liver Transpl. 2001;7(12):1088-1089.

23. Watanabe T, Katsukura H, Shirai Y, et al. Helper CD4+ T cells for IgE response to a dietary antigen develop in the liver. J Allergy Clin Immunol. 2003;111(6):1375-1385.

24. Brown C, Haringman N, Davies C, et al. High prevalence of food sensitisation in young children with liver disease: a clue to food allergy pathogenesis? Pediatr Allergy Immunol. 2012;23(8):771-778.

25. Boyle RJ, Hardikar W, Tang ML. The development of food allergy after liver transplantation. Liver Transpl. 2005;11(3):326-330.

26. Topal E, Catal F, Selimoglu MA, et al. Acquired atopic disease after liver transplantation in children; similarities to and differences from adults: a preliminary study. Eur J Gastroenterol Hepatol. 2014;26(9):1055-1059.

27. Lee Y, Lee YM, Kim MJ, Lee SK, Choe YH. Long-term follow-up of de novo allergy in pediatric liver transplantation $10 \mathrm{yr}$ experience of a single center. Pediatr Transplant. 2013;17(3):251-255.

28. van Sandwijk MS, Bemelman FJ, Ten Berge IJ. Immunosuppressive drugs after solid organ transplantation. Neth JMed. 2013;71(6):281-289.

29. Gruber S, Tiringer K, Dehlink E, et al. Allergic sensitization in kidneytransplanted patients prevails under tacrolimus treatment. Clin Exp Allergy. 2011;41(8):1125-1132.

30. Ozdemir O. New developments in transplant-acquired allergies. World J Transplant. 2013;3(3):30-35.

31. Lykavieris P, Frauger E, Habes D, Bernard O, Debray D. Angioedema in pediatric liver transplant recipients under tacrolimus immunosuppression. Transplantation. 2003;75(1):152-155. 
32. Granot E, Yakobovich E, Bardenstein R. Tacrolimus immunosuppression - An association with asymptomatic eosinophilia and elevated total and specific IgE levels. Pediatr Transplant. 2006;10(6):690-693.

33. Asante-Korang A, Boyle GJ, Webber SA, Miller SA, Fricker FJ. Experience of FK506 immune suppression in pediatric heart transplantation: a study of long-term adverse effects. J Heart Lung Transplant. 1996;15(4):415-422.

34. Nowak-Wegrzyn AH, Sicherer SH, Conover-Walker MK, Wood RA. Food allergy after pediatric organ transplantation with tacrolimus immunosuppression. J Allergy Clin Immunol. 2001;108(1):146-147.

35. Chehade M, Nowak-Wegrzyn A, Kaufman SS, Fishbein TM, Tschernia A, LeLeiko NS. De novo food allergy after intestinal transplantation: a report of three cases. J Pediatr Gastroenterol Nutr. 2004;38(5):545-547.

36. Castells M, Boyce J. Transfer of peanut allergy by a liver allograft. N Engl J Med. 1998;338(3):202-203.

37. Ozbek OY, Ozcay F, Avci Z, Haberal A, Haberal M. Food allergy after liver transplantation in children: a prospective study. Pediatr Allergy Immunol. 2009;20(8):741-747.

38. Phan TG, Strasser SI, Koorey D, et al. Passive transfer of nut allergy after liver transplantation. Arch Intern Med. 2003;163(2):237-239.

39. Garzorz N, Thomas J, Eberlein B, et al. Newly acquired kiwi fruit allergy after bone marrow transplantation from a kiwi-allergic donor. J Eur Acad Dermatol Venereol. 2016;30(7):1136-1139.

40. Dehlink E, Gruber S, Eiwegger T, et al. Immunosuppressive therapy does not prevent the occurrence of immunoglobulin E-mediated allergies in children and adolescents with organ transplants. Pediatrics. 2006;118(3):e764-e770.

41. Madsen KL, Yanchar NL, Sigalet DL, Reigel T, Fedorak RN. FK506 increases permeability in rat intestine by inhibiting mitochondrial function. Gastroenterology. 1995;109(1):107-114

42. Gabe SM, Bjarnason I, Tolou-Ghamari Z. The effect of tacrolimus (FK-506) on intestinal barrier function and cellular energy production in humans. Gastroenterology. 1998;115(1):67-74.

43. Cardet JC, Boyce JA. Addition of mycophenolate mofetil to tacrolimus is associated with decreases in food-specific IgE levels in a pediatric patient with liver transplantation-associated food allergy. J Allergy Clin Immunol Pract. 2013;1(1):104-106.

44. Noble C, Peake J, Lewindon PJ. Increase in de novo allergies after paediatric liver transplantation: the Brisbane experience. Pediatr Transplant. 2011:15(5):451-454

45. Ozdemir O, Arrey-Mensah A, Sorensen RU. Development of multiple food allergies in children taking tacrolimus after heart and liver transplantation. Pediatr Transplant. 2006;10(3):380-383.

46. Vagefi PA, Blazick E, Hamilos D, Ades A, Cosimi AB, Hertl M. Transference of food allergy after adult liver transplantation. Transplantation. 2009;87(9):1426.
47. Pacifico L, Frediani T, Simonetti A, Chiesa C, Cucchiara S. Tacrolimus and food allergy. Transplantation. 2003;76:1778.

48. Dewachter P, Vezinet C, Nicaise-Roland P, et al. Passive transient transfer of peanut allergy by liver transplantation. Am J Transplant. 2011;11(7):1531-1534.

49. Inui A, Komatsu H, Fujisawa T. Food allergy and tacrolimus. J Pediatr Gastroenterol Nutr. 1999;28:355-356.

50. Arikan C, Kilic M, Tokat Y, Aydogdu S. Allergic disease after pediatric liver transplantation with systemic tacrolimus and cyclosporin a therapy. Transplant Proc. 2003;35(8):3039-3041.

51. Saeed SA, Integlia MJ, Pleskow RG, et al. Tacrolimus-associated eosinophilic gastroenterocolitis in pediatric liver transplant recipients: role of potential food allergies in pathogenesis. Pediatr Transplant. 2006;10(6):730-735.

52. De Bruyne R, Dullaers M, Van Biervliet S, et al. Post-transplant food allergy in children is associated with liver and not with renal transplantation: a monocentric comparative study. Eur J Pediatr. 2013;172(8):1069-1075.

53. Frischmeyer-Guerrerio PA, Wisniewski J, Wood RA, Nowak-Wegrzyn A. Manifestations and long-term outcome of food allergy in children after solid organ transplantation. J Allergy Clin Immunol. 2008;122(5):10311033.e1.

54. Berry A, Campsen J, Shihab F, Firszt R. Transfer of peanut IgE sensitisation after combined pancreas-kidney transplant. Clin Exp Allergy. 2014;44(8):1020-1022.

55. Bhinder S, Heffer MJ, Lee JK, Chaparro C, Tarlo SM. Development of transient peanut allergy following lung transplantation: a case report. Can Respir J. 2011;18(3):154-156.

56. Schuller A, Barnig C, Matau C, et al. Transfer of peanut allergy following lung transplantation: a case report. Transplant Proc. 2011;43(10): 4032-4035.

57. Khalid I, Zoratti E, Stagner L, Betensley AD, Nemeh H, Allenspach L. Transfer of peanut allergy from the donor to a lung transplant recipient. $J$ Heart Lung Transplant. 2008;27(10):1162-1164.

58. Inoue Y, Ochiai H, Hishiki T, Shimojo N, Yoshida H, Kohno Y. Food allergy after cord blood stem cell transplantation with tacrolimus therapy in two patients who developed veno-occlusive disease. Allergol Int. 2012;61(3):497-499.

59. Bellou A, Kanny G, Fremont S, Moneret-Vautrin DA. Transfer of atopy following bone marrow transplantation. Ann Allergy Asthma Immunol. 1997;78(5):513-516.

60. Yong PF, Grosse-Kreul D, Devereux S, Pagliuca A, Maher J, Ibrahim MA. Increase in allergy following donor lymphocyte infusions. Bone Marrow Transplant. 2006;37(10):983-984.
Journal of Asthma and Allergy

\section{Publish your work in this journal}

The Journal of Asthma and Allergy is an international, peer-reviewed open access journal publishing original research, reports, editorials and commentaries on the following topics: Asthma; Pulmonary physiology; Asthma related clinical health; Clinical immunology and the immunological basis of disease; Pharmacological interventions and new therapies. This journal is included in PubMed. The manuscript management system is completely online and includes a very quick and fair peer-review system, which is all easy to use. Visit http://www. dovepress.com/testimonials.php to read real quotes from published authors. 